\title{
Exploration of Introducing the Guidance of Innovation and Entrepreneurship in the Education of Ideology and Politics in Colleges
}

\author{
Xiaoni Zhang \\ Xi'an Peihua University, Xi’an, Shaanxi, 710125
}

Keywords: Colleges and universities; ideological and political education; innovation and entrepreneurship guidance

\begin{abstract}
From the perspectives of economic and social development, promotion of social harmony and stability, and contemporary college students' practical needs, this article first explores the significance of introducing innovation and entrepreneurship guidance into the ideological and political education in colleges and universities. It points out that introducing innovation and entrepreneurship guidance into ideological and political education not only helps to improve ideological and political education The effectiveness of education, but also enhance the scientific guidance of innovation and entrepreneurship. Secondly, it summarizes the correlation between ideological and political education in universities and the goal of innovation and entrepreneurship guidance, and reflects on the tentative exploration of introducing innovation and entrepreneurship guidance in the ideological and political education in colleges and universities. Finally, some practical experiences are concluded, including: implanting the guiding module of innovation and entrepreneurship in the curriculum system of ideological and political education; building the related campus cultural atmosphere; building a social practice platform of interactive interaction between the two; cultivating "dual energy" faculty; The combination of theory and practice and the establishment of a corresponding system of coordination and reform so that the guidance for innovation and entrepreneurship can be professionalized.
\end{abstract}

\section{Introduction}

The introduction of innovation and entrepreneurship guidance into the ideological and political education in colleges and universities is a pioneering undertaking of higher education in contemporary China, the only way to vigorously develop innovation and pioneering education, and is also a new direction for the development of ideological and political education in colleges and universities. Colleges and universities should broaden their work train of thought, enhance the ability of education and scientific research, market analysis and prediction, and fully prepare for the effective guidance of innovation and entrepreneurship. College teachers should actively strengthen their own learning, strive to broaden the field of theoretical knowledge, strengthen the practical ability of innovation and entrepreneurship, on the basis of which to explore the innovation and entrepreneurship guidance into the concrete implementation of ideological and political education in colleges and universities.

First, the ideological and political education in colleges and universities to introduce the significance of innovation and entrepreneurship guidance

The introduction of innovation and entrepreneurship guidance into the ideological and political education in universities is not only necessary to improve the effectiveness of ideological and political education, but also to enhance the scientific guidance of innovation and entrepreneurship. In particular, it is worth noting that the introduction of innovative and pioneering guidance into the ideological and political education is necessary for economic and social development, which can promote social harmony and stability and is also the need of contemporary college students. The specific analysis is as follows.

The introduction of innovation and entrepreneurship guidance into the ideological and political education in colleges and universities is an urgent need of innovation-driven development, adjustment of economic structure and acceleration of industrial upgrading. It is necessary for the 
implementation of the national strategy of public innovation and entrepreneurship, and is the demand of higher education institutions to meet the needs of the society, reflecting their social service functions The inevitable, but also cultivate the innovative ability of college students, entrepreneurship and make it a realistic path to high-quality talent [2]. Therefore, in the ideological and political education in college students under the guidance of innovation and entrepreneurship under the conditions of market economy, social development for the basic requirements of colleges and universities.

With the rapid development of socialist market economy in our country and the change in the employment situation with a great number of jobs, in recent years our government has paid great attention to the employment of college graduates and has introduced various preferential policies to encourage college students to start their own businesses. In the "13th Five-Year Plan" Proposed to vigorously promote the "employment to promote employment," the gradual implementation of the relevant policies. At the same time, all sectors of society are paying more attention to the employment and entrepreneurship of undergraduates. This makes the reform of college education from content to form an inevitable trend, employment guidance for college students and entrepreneurship education have been carried out in an orderly manner [3]. Doing ideological and political work of college students' innovation and entrepreneurship not only strengthens the effectiveness of ideological and political education in universities, but also benefits the effective implementation of the national employment policy.

Students tend to be more curious about the new things in society, and curiosity will stimulate their interest in learning and the desire to actively explore. However, due to the shallow experience of college students, the lack of social practical experience and ability to make decisions, analysis and problem solving often remain in the theoretical level, coupled with inaccurate understanding of their own capabilities, there are usually ambiguous positioning, the lack of specific directions and goals of efforts and other issues, Its psychological quality, especially anti-frustration generally poor. Innovation and entrepreneurship guidance is one of the goals of taking education as a core, self-learning, self-development and self-management as its core competence and an important measure for promoting quality-oriented education in an all-round way. Originally, it should be ideological and political education an important aspect, the introduction of innovative entrepreneurship guidance in the ideological and political education is the reality of contemporary college students need [4].

\section{Innovation and entrepreneurship guidance and ideological and political education in colleges and universities integration of the existing problems}

At present, there are still some deficiencies in the field of innovation and entrepreneurship education in higher education as follows: on the one hand, they pay insufficient attention to the cause of innovation and entrepreneurship and education, especially the system of higher education has not been fully developed; on the other hand, it has simplified the education of entrepreneurship and entrepreneurship, Treat it as a start-up enterprise education, neither to solve the problems of curriculum, teachers, achievement transformation, platform construction, education mechanism, etc., nor really to "teacher + student + social enterprise" innovation and entrepreneurship education model Teaching activities. The guidance of innovation and entrepreneurship is a "pragmatic" education. The content of education is closely related to the actual interests of adult students. However, there still exists a tendency of education in the education sector in China and the society as a whole. The disregard of high-quality innovative and pioneering talents Culture.

At present, from the perspective of top-level design, innovation and entrepreneurship education has not yet been incorporated into the training programs for undergraduates. It is more difficult to integrate into the curriculum system of higher education at the operational level, and more difficult to integrate into all aspects of professional education. Instead, entrepreneurship education is usually conducted in the form of elective courses or short-term training. Elective or training forms can help start-up students to learn the knowledge and skills of innovation and entrepreneurship. However, after all, the basic teaching skills are weak, the coverage is small, and it is difficult to improve 
learners' practical skills in innovation and entrepreneurship.

The development of innovation and entrepreneurship education for adult college students needs to be based on social practice. Only when adult education institutions make more efforts to strengthen practical education can they achieve the desired educational effect. However, adult education institutions generally do not pay attention to build a social practice platform for adult college students, fewer arrangements for field trips, extracurricular practice projects, less innovation and entrepreneurship practice, the basic does not hold entrepreneurship contest and innovation venture exchange meeting, many adult students to the country Lack of understanding of policies related to innovation and entrepreneurship, enthusiasm for innovation and entrepreneurship needs to be stimulated. Under such circumstances, there is hardly any linkage between innovation and entrepreneurship guidance and professional education.

\section{To Solve the integration of adult education innovation and entrepreneurship education and professional education of the development of countermeasures}

Adult education institutions must be clear and innovative Entrepreneurship guidance is an important part of adult education, and strive to create a culture of innovation and entrepreneurship guidance and professional education, unify the adult education workers and educators, the formation of innovation and entrepreneurship guidance and professional education integration The teaching style and style of study. In the implementation, the following approaches can be taken: (1) To carry out the innovative and diverse special education activities that are positive and progressive, as well as science and technology, academia, sports, arts and entertainment activities, and vigorously create the style of innovation and entrepreneurship; (2) To organize and participate in the innovation and entrepreneurship competition to guide into education Students carry forward the gritty, diligent and friendly spirit of innovation and entrepreneurship, to enhance teamwork skills and awareness, and exercise their innovative entrepreneurial competitive ability; (3)Institutions of innovation and entrepreneurship and other activities to encourage adult students of innovation and entrepreneurship, vigorously promote innovation and entrepreneurship guidance and professional The Convergence and Development of Education.

In view of the serious shortage of self-owned funds, the institutions of adult education should pay attention to the integration of various elements of adult education, social practice and scientific research, and work together to achieve the integration of innovation and entrepreneurship education and professional education [5]. We should vigorously promote entrepreneurship, entrepreneurial capabilities and entrepreneurial quality, the establishment of venture capital funds and professional innovation and entrepreneurship services for adult students in the innovation and entrepreneurs to provide the appropriate start-up funds and related services. Entrepreneurial competence and entrepreneurial quality training should be practiced. Adult education institutions should provide practical college students with opportunities, environments and conditions, establish an innovation and entrepreneurship education base, and organize and participate in business practice activities purposefully and systematically. Also attach great importance to innovation and entrepreneurship practice, combined with the actual needs of enterprises, industries and the community, to vigorously carry out employment orientation of graduates of adult education and employment quality follow-up investigation, regular contact, keep abreast of their job position changes, job changes, remuneration packages, job satisfaction, etc. Situation, to better enhance the effectiveness of adult education.

In view of the shortage of teachers, the countermeasures that the transaction system can take are as follows: Firstly, broaden the training channels and methods of teacher training by organizing entrepreneurship exchanges and educational internships so as to enhance the overall teaching ability and level of the adult education faculty; secondly, to carry out innovation and entrepreneurship groups Counseling activities, the establishment of workshops, the salon and other professional development to enhance professionalism; third is to help adult education workers to establish career development goals, so as to adapt to the new situation as soon as possible; fourth is to organize 
adult education teachers to volunteer service and other social Activities, lay the foundation for the career development of "dual-capable" teachers. Fifth, some teachers will be trained as "academics and entrepreneurs" or "academic entrepreneurs", making them the backbone of innovation and entrepreneurship guidance, and gradually realizing the specialization of innovation and entrepreneurship guidance.

Adult education institutions should establish expert think tanks and innovative think tanks to enrich and optimize the teaching staff for entrepreneurship education. To establish a development mechanism for mutual hiring teachers with ordinary colleges and universities to realize the full use of the strengths of teachers. Through the training of teachers, they should be fully aware of The value of entrepreneurship education, and then proficiency in professional theory at the same time, with innovative entrepreneurial counseling and counseling practice ability. Adult education teachers should rely on all levels of school-enterprise cooperation platform and collaborative innovation center, take the initiative to take part in industry, enterprise product development, design and innovation and upgrading, improve their own practice and innovation ability.

The author believes that the gradual and orderly approach can be incorporated into the guidance of innovation and entrepreneurship adult education programs and curriculum system. The first step is the organic integration of classroom teaching and extracurricular activities to guide adult students to actively participate in scientific research and various professional competitions, arrange all kinds of field trips, extracurricular practice projects, organize entrepreneurship competitions and innovation entrepreneurship and exchange conferences, inspire students to innovate Entrepreneurial interest and enthusiasm, focus on cultivating its gritty quality and positive attitude, as well as the establishment of a positive concept of employment and entrepreneurship, to stimulate their hard work and pioneering and innovative spirit. At the same time, we should focus on shaping a good psychological quality of innovation and entrepreneurship, focusing on the characteristics of will and emotion, cultivating the ability of adult college students to solve problems independently, adapting to the surrounding environment, and team spirit. The second step is to directly cultivate the contents of innovation and entrepreneurship in the professional education curriculum. By taking advantage of traditional professional education, we can incorporate innovation and entrepreneurship guidance into professional curriculum teaching and teach entrepreneurship and professional knowledge through lectures, lectures and group exchanges Communication skills and communicative means. At the same time, an innovation and entrepreneurship education base should be set up to provide training environment and conditions for adult college students and to organize adult college students to engage in commercial activities in a planned and targeted manner. The third step is to introduce the innovation and entrepreneurship guidance into the professional education curriculum system, which is based on the professional education curriculum. The theoretical teaching should also be based on guided and interactive participatory teaching methods. When the conditions are ripe, we can reorganize the professional knowledge pertinently according to the actual needs of entrepreneurship and establish an integrated teaching mode of "school-enterprise cooperation", "school-enterprise cooperation" and "production, study and research" and strengthen the entrepreneurship base both inside and outside the school Construction, practical ability, ability of innovation and entrepreneurship as the main line to build education modules, until the innovation and entrepreneurship education has not yet included into the program of adult education students.

The concrete implementation method includes establishing the education system of entrepreneur from two aspects of compulsory courses and elective courses, and facing the teaching plan of adult undergraduates pursuing advanced studies and cultivating their entrepreneurial abilities. More realistic and feasible approach is: In the professional education curriculum system, the implantation of innovative teaching module, requires that all adult students must obtain the appropriate credit in order to enhance their enthusiasm to learn the professional knowledge. It is helpful to cultivate students' awareness of self-reliance, competition, innovation, practice, ethics and sense of social responsibility. It helps students establish a correct sense of career choice and entrepreneurial awareness, Develop an independent personality qualities, a certain degree of professionalism and skills, and a good team spirit. 
Adult education institutions should actively seek the support of venture capital funds and attract idle social funds to set up innovation and entrepreneurship funds, so as to establish entrepreneurship demonstration bases for students, innovation and entrepreneurship parks, entrepreneurship incubation bases, entrepreneurial clubs, venture studios and online marketing platforms. Platform; adhere to the organic combination of industry, academia and research of collaborative innovation and development, encourage and attract the support of various social sectors, the establishment of business associations, business clubs, through the organization of business plan competitions, career planning competitions, and declare commitment to innovation and entrepreneurship training programs, To organize a variety of extracurricular entrepreneurial and cultural activities; Through entrepreneurship sand table, business games and other forms, simulation and founding and running enterprises, so that learners can experience the founder and the operation of the whole process of enterprises to increase the intuitive experience of students to start business to make it better To grasp the entrepreneurial theory and social practice combined. To build a social practice platform can also promote the undergraduates concerned about the disadvantaged groups and social issues so that they can develop good characters full of love, compassion and sense of social responsibility. Through various practical activities and "research-study-oriented" activities, to study new problems, to explore the pioneering and innovative spirit of new ideas, and to be passionate, sober and rational, to establish a sound foundation for their true start-up.

In summary, the introduction of innovation and entrepreneurship guidance into the ideological and political education in higher education institutions is a pioneering undertaking of higher education in contemporary China. In the future, we should pay more attention to the in-depth integration of science, technology and humanities in the specific implementation process. The author thinks that we can learn from the online and offline one-stop hybrid education mode of Longhua Garden "Internet + self-media" to provide full-time and personalized guidance and help to college students. The implementation of "Internet plus self-media" education mode enables educators and college students to communicate with each other anytime, anywhere so that they can confide in their teachers when they are confused, which helps teachers keep abreast of all aspects of their students' learning and life so as to ensure their daily education and management work smoothly.

\section{References}

[1] Yu Zhanhong. Innovation and entrepreneurship education under the guidance of ideological and political education in the overall design reform [J]. Higher Education, 2015 (13): 13-15.

[2] Wang Xin. On the core values under the guidance of innovation and entrepreneurship education of college students a theoretical discussion [J]. Business, 2015 (6): 41-42.

[3] Wang Shao Lang. Pioneering teachers in innovation and entrepreneurship education in higher education positioning and role [J]. China's Graduate Employment, 2015 (4): 13-16.

[4] Chen Zhe. Innovation and entrepreneurship education embedding ideological and political education mode of operation [J]. School Party Building and Ideological Education, 2015 (13): 53-55.

[5] Jia Yong. Practice of Strengthening Entrepreneurship and Employment Guidance [J]. Journal of Labor and Social Security, 2015 (5): 14-15. 